\title{
Minimally Invasive Pyeloplasty in Horseshoe Kidneys with Ureteropelvic Junction obstruction: A case series
}

\author{
Stephen Faddegon, Candace Granberg, Yung K Tan, Patricio C. Gargollo, Jeffrey A. Cadeddu \\ Department of Urology, University of Texas Southwestern Medical Center, Dallas, TX, USA
}

\section{ABSTRACT}

Background and Purpose: Horseshoe kidney is an uncommon renal anomaly often associated with ureteropelvic junction (UPJ) obstruction. Advanced minimally invasive surgical (MIS) reconstructive techniques including laparoscopic and robotic surgery are now being utilized in this population. However, fewer than 30 cases of MIS UPJ reconstruction in horseshoe kidneys have been reported. We herein report our experience with these techniques in the largest series to date.

Materials and Methods: We performed a retrospective chart review of nine patients with UPJ obstruction in horseshoe kidneys who underwent MIS repair at our institution between March 2000 and January 2012. Four underwent laparoscopic, two robotic, and one laparoendoscopic single-site (LESS) dismembered pyeloplasty. An additional two pediatric patients underwent robotic Hellstrom repair. Perioperative outcomes and treatment success were evaluated.

Results: Median patient age was 18 years (range 2.5-62 years). Median operative time was 136 minutes (range 109-230 min.) and there were no perioperative complications.

After a median follow-up of 11 months, clinical (symptomatic) success was 100\%, while radiographic success based on MAG-3 renogram was 78\%. The two failures were defined by prolonged $t_{1 / 2}$ drainage, but neither patient has required salvage therapy as they remain asymptomatic with stable differential renal function.

Conclusions: MIS repair of UPJ obstruction in horseshoe kidneys is feasible and safe. Although excellent short-term clinical success is achieved, radiographic success may be lower than MIS pyeloplasty in heterotopic kidneys, possibly due to inherent differences in anatomy. Larger studies are needed to evaluate MIS pyeloplasty in this population.

\section{ARTICLE INFO}

\section{Key words:}

Kidney; Laparoscopy;

Robotics; Surgical

Procedures, Minimally

Invasive

Int Braz J Urol. 2013; 39: 195-202

Submitted for publication:

April 24, 2012

Accepted after revision:

December 21, 2012

\section{INTRODUCTION}

Horseshoe kidney is a renal fusion anomaly characterized by renal malrotation, variable blood supply, high insertion of the ureter, and a propensity to form ureteropelvic junction (UPJ) obstruction in up to one third of cases (1). Since first being introduced in 1993 (2), minimally invasive pyeloplasty has become the gold standard for the treatment of UPJ obstruction (3). In heterotopic kidneys, success rates range between 90 and 100\% (2,4,5). However, there are limited published series of MIS pyeloplasty for UPJ obstruction in horseshoe kidneys. Since the first case report in 1996 (6), fewer than 30 cumulative cases have been reported in the literature, with the largest individual case series consisting of 5 patients (7). These sparse reports may reflect the relative rarity of horseshoe UPJ obstruction, but may also relate to a perceived increase in surgical difficulty due to unfamiliar and variable anatomy. 
Currently, there is no consensus regarding the optimal surgical approach for the treatment of horseshoe UPJ obstruction. We herein report our experience with various MIS approaches, which to our knowledge is the largest series to date.

\section{MATERIALS AND METHODS}

\section{Patients}

We conducted a retrospective review of consecutive patients with a horseshoe UPJ obstruction treated with MIS techniques at our institution from March 2000 to January 2012. Twelve patients were identified, but three patients were excluded because postoperative renography studies were not available as they moved away shortly following their surgeries and despite intense efforts, could not be reached. The study received Institutional Review Board approval. Four pediatric patients $(\leq 18$ years old) were treated by a pediatric urologist and the remainder by an adult minimally invasive surgeon. Indication for surgery was ipsilateral flank pain in eight patients, and urinary tract infection in one patient, with confirmation of UPJ obstruction by lasix renography in each case. Additional preoperative evaluation included a CT scan (Figure-1), IVP and/or renal ultrasound.

The surgical approach was determined by surgeon preference and body habitus. All robotic pyeloplasties were performed by one pediatric urologist, while the laparoscopic cases were performed by one adult urologist. The case of LESS pyeloplasty was chosen based on the favorable BMI of the patient.

\section{Surgical techniques}

A transperitoneal approach was used in each case. Five adult patients were treated including four that underwent conventional laparoscopic dismembered pyeloplasty, and one that underwent conventional laparoendoscopic single-site (LESS) dismembered pyeloplasty. Four pediatric patients were treated via a robotic approach including two that underwent dismembered pyeloplasty and two that underwent Hellstrom repair (Table-1).

For each approach, patients were placed in a flexed, lateral decubitus position. For conventional
Figure 1 - CT scan demonstrating right UPJ obstruction of a horseshoe kidney.

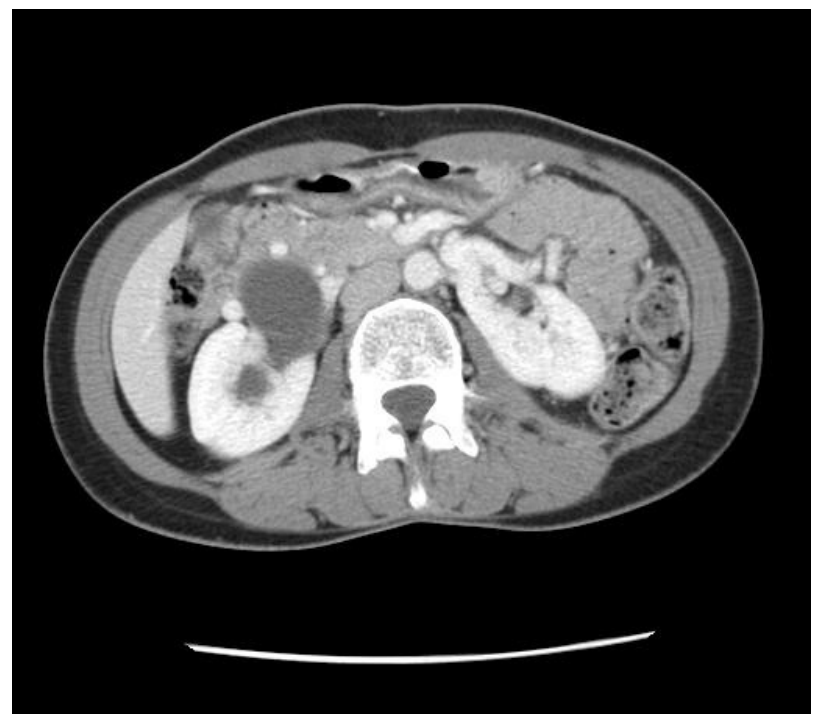

Table 1 - Patient Characteristics.

\begin{tabular}{lc}
\hline Age (Median + Range) & 18 years [2.5, 62] \\
\hline Male & $8 / 9(89 \%)$ \\
Race & \\
$\quad$ Caucasian & $7 / 9(78 \%)$ \\
$\quad$ Hispanic & $2 / 9(22 \%)$ \\
BMI (Median + Range) & $23[17,32.5]$ \\
Left side & $8 / 9(89 \%)$ \\
Crossing vessel & $7 / 9(78 \%)$ \\
Primary UPJO & $8 / 9(89 \%)$ \\
Calculus present & $2 / 9(22 \%)$ \\
Prior abdominal surgery & $2 / 9(22 \%)$ \\
Surgical technique (N) & \\
$\quad$ Conventional Lap dismembered & 4 \\
Robotic dismembered & 2 \\
Robotic Hellstrom vascular hitch & 2 \\
C-LESS dismembered & 1 \\
\hline
\end{tabular}


laparoscopy, 3 ports including a 10/12 mm umbilical camera port, a mid-clavicular subcostal 10/12 $\mathrm{mm}$ port, and a mid-clavicular $5 \mathrm{~mm}$ lower quadrant port were used. The working ports were positioned more inferiorly on the abdomen than heterotopic cases. The robotic approach required 3-4 ports: a 10/12 $\mathrm{mm}$ camera port at the umbilicus, two $8 \mathrm{~mm}$ robotic ports, and an optional assistant port in the lower quadrant. The LESS pyeloplasties were performed through a $2.5 \mathrm{~cm}$ incision at the umbilicus through which three ports $(2 \times 5 \mathrm{~mm}, 1 \times 10 \mathrm{~mm})$ were positioned in a triangular fashion through the anterior abdominal fascia. During LESS, a $5 \mathrm{~mm} 45$ degree laparoscope was used along with articulating instruments (Real Hand, Novare, CA) that crossed within the abdomen. The laparoscope was placed through the most medial trocar and positioned anteriorly in the abdomen, looking down onto the surgical field. For right-sided cases, a 3-5 mm xyphoid instrument was used, if necessary, for liver retraction.

The principles of dissection were uniform regardless of approach utilized. The colon was reflected medially and the ureter isolated distally. Due to the low renal position in horseshoe kidneys, the ureter was isolated in closer proximity to the iliac and other pelvic vessels. The ureter and renal pelvis were dissected within Gerota's fascia. Direct manipulation of a crossing vessel, if present, was avoided to prevent vessel injury and potential compromise of lower pole parenchyma. Instead, traction on the ureter and pelvis was alternated to expose the attachments to the vessel until the ureter would slide freely beneath it.

Indwelling JJ ureteral stents were placed in eight of the nine cases. We prefer antegrade stent placement for both the laparoscopic and robotic approaches to avoid the additional operative time required for cystoscopy and retrograde placement at the beginning of the case. For LESS surgery, however, we prefer retrograde stent placement because of the lack of an upper quadrant port that provides the optimal angle for antegrade placement.

The anastamosis was performed using running 3-0 polyglactin suture. During LESS pyeloplasty, a $5 \mathrm{~mm}$ accessory mid-axillary port (subsequently used for the surgical drain) was placed to facilitate triangulation during the anastomosis. Postoperatively Foley catheter drainage was conti- nued for 24-48 hours. Drain output was monitored after Foley removal and if stable, the drain was discontinued. Ureteral stents were removed 4-6 weeks postoperatively.

Two pediatric patients were treated with a 'vascular hitch' (Hellstrom) procedure. After complete mobilization of the ureter from the vessels, normal peristalsis across the UPJ and the absence of an obvious intrinsic stricture was confirmed visually. The lower pole vessels were then affixed in a cephalad position away from the UPJ by imbricating the redundant pelvic wall over the vessels with 2-3 absorbable sutures, similar to the approach described by Gundeti et al. (8).

Treatment success was determined with both clinical and radiographic follow-up. Clinical (symptomatic) success was defined as an absence of recurrent flank pain or other clinical condition attributable to UPJ obstruction (e.g. recurrent urinary tract infections or recurrent renal calculi). Radiographic success was defined as stable differential function (no greater than 10\% decrease) and $t_{1 / 2}$ drainage of less than 20 minutes on postoperative lasix renogram. One exception was made to this definition in a patient undergoing robotic dismembered pyeloplasty. Despite having a postoperative $t_{1 / 2}$ of 27.3 minutes, his preoperative $t_{1 / 2}$ was greater than 50 minutes and the differential function of the ipsilateral moiety improved from $38 \%$ to $62 \%$, demonstrating clearly that an obstruction no longer existed. The prolonged $t_{1 / 2}$ was presumably secondary to a redundant pelvis.

Descriptive statistics for demographic, clinical and postoperative outcomes are reported. By nature of the small sample size, our data is non-normally distributed so we report non-parametric tests (median, range). There was insufficient statistical power for a robust statistical analysis.

\section{RESULTS}

Median patient age was 18 years (range 2.562). Median body mass index (BMI) was 25 (range 17-32.5). Eight were male, 89\% had left sided UPJ obstruction, and 78\% had crossing vessel pathophysiology. Eight patients had a primary UPJ obstruction, while one patient's obstruction was thought to be secondary to stone disease (Table-1). 
The overall median operative time was 136 minutes (range 109-230) with a median blood loss of 12.5 cc (range 5-50). There were no perioperative complications. All except one patient had a ureteral stent placed intraoperatively; one pediatric patient underwent unstented Hellstrom repair. The median length of stay was 1.5 days (range 1-4 days) (Table-2).

Clinical success was $100 \%$ after a median follow-up of 11 months (range 3-45). Follow-up imaging consisted of a minimum of one lasix MAG-3 renogram obtained at least 3 months from the surgery date. Six patients underwent a single postoperative renogram, while two patients had four renograms and one patient had two. The median differential function at last follow-up was 48\% (range 24-62\%), unchanged from 51\% (ran- ge $28-71 \%$ ) preoperatively. The median drainage $\mathrm{t}_{1 / 2}$ decreased substantially from 45 minutes (range 20-50) to 13 minutes (range 3.5-41) (Table-3). At last follow-up, seven of nine patients (78\%) with postoperative renograms showed radiographic success. The two patients who failed by renographic follow-up had undergone laparoscopic pyeloplasty. The first patient had unobstructed drainage on a renogram obtained at 9 months $\left(\mathrm{t}_{1 / 2}\right.$ = 11 minutes), but at last follow-up (30 months), demonstrated evidence of re-obstruction $\left(\mathrm{t}_{1 / 2}=\right.$ 31.6 minutes). The second patient demonstrated a persistently prolonged $t_{1 / 2}$ of 40.8 minutes at three months $\left(t_{1 / 2}\right.$ was not reached on the preoperative study). Nevertheless, both patients remained asymptomatic with stable differential function and have not required any further intervention.

Table 2 - Perioperative outcomes by MIS approach.

\begin{tabular}{|c|c|c|c|c|c|}
\hline & Laparoscopy & Robot & Robot & c-LESS & Overall \\
\hline Technique & Dismembered & Dismembered & Hellstrom & Dismembered & \\
\hline N & 4 & 2 & 2 & 1 & 9 \\
\hline Year of Surgery & 2008- 2012 & 2010 & 2011 & 2008 & $2008-2012$ \\
\hline $\begin{array}{l}\text { BMI } \\
\text { (Median \& range) }\end{array}$ & $29.9[27.1,32.5]$ & $21[19,23]$ & $19.5[17,22]$ & 19.1 & $25[17,32.5]$ \\
\hline $\begin{array}{l}\text { OR time, mins } \\
\text { (Median \& range) }\end{array}$ & $149.5[109,230]$ & $138[120,155]$ & $126[115,137]$ & 204 & $136[109,230]$ \\
\hline $\begin{array}{l}\text { Blood loss, } \mathrm{mL} \\
\text { (Median \& range) }\end{array}$ & $50[20,50]$ & $5[5,5]$ & $5[5,5]$ & 50 & $12.5[5,50]$ \\
\hline $\begin{array}{l}\text { Length of Stay, days } \\
\text { (Median \& range) }\end{array}$ & $3[2,4]$ & $1[1,1]$ & $1[1,1]$ & 3 & $1.5[1,4]$ \\
\hline Perioperative complication & None & None & None & None & None \\
\hline $\begin{array}{l}\text { Follow-up Duration, months } \\
\text { (Median \& range) }\end{array}$ & $25.5[3,45]$ & $15[12.5,17]$ & $7[6,8]$ & 31 & $11[3,45]$ \\
\hline Clinical success & $100 \%$ & $100 \%$ & $100 \%$ & $100 \%$ & $100 \%$ \\
\hline Radiographic success & $50 \%$ & $100 \%$ & $100 \%$ & $100 \%$ & $78 \%$ \\
\hline
\end{tabular}


Table 3 - Functional Outcomes.

\begin{tabular}{lcc}
\hline & Preoperative & $\begin{array}{c}\text { Postoperative } \\
\text { (At last follow-up) }\end{array}$ \\
\hline $\begin{array}{l}\text { Differential function, \%* } \\
\text { (Median + Range) }\end{array}$ & $51[28,71]$ & $48[24,62]$ \\
$\begin{array}{l}\mathrm{t}_{1 / 2} \text { drainage, }{ }^{*} \text { mins } \\
\text { (Median + Range) }\end{array}$ & $45[20,50]$ & $13[3.5,41]$ \\
$\%$ Symptomatic & $100 \%$ & $0 \%$ \\
\hline
\end{tabular}

*Refers to Ipsilateral Renal Moiety

Outcomes were also analyzed according to surgical approach. Median BMI for the laparoscopy group was higher than that for the robotic or LESS groups. Median OR time for robotic and conventional laparoscopy was shorter than the LESS group, while median hospital length of stay was shorter for patients treated via a robotic approach. While these differences are noted, there are insufficient patient numbers to allow an appropriate statistical comparison (Table-2).

\section{DISCUSSION}

The largest series to date on pyeloplasty for horseshoe UPJ obstruction report outcomes for open Foley Y-V plasty and they generally lack reporting of both radiologic and clinical follow up which is now standard (9). Nevertheless, open surgery success rates in horseshoe kidneys were less favorable than in orthotopic kidneys, ranging from 55 to $80 \%(9,10)$ compared to over $90 \%$ respectively $(11,12)$. In comparison, success rates of endopyelotomy in horseshoe kidneys range from $66-75 \%$ based on three small series, each containing just 3-4 patients $(1,13,14)$. Again, these success rates are less favorable than for endopyelotomy in orthotopic kidneys, which range from 77 to $89 \%(15,16)$ with absent crossing vessels, and less than 70\% in the presence of a crossing vessel. The overall radiographic success rate of $78 \%$ in this study is thus comparable to success rates reported for open pyeloplasty in horseshoe kidneys $(9,10)$. Smaller series of hor- seshoe MIS pyeloplasty are limited to cohorts of five or fewer patients, and report success rates ranging from $66 \%$ to $100 \%(1,7,17)$ (Table-4). Together, these data would suggest that horseshoe UPJO has a greater propensity for failure than orthotopic kidneys.

Although 78\% is inferior to the greater than $90 \%$ success rate for MIS pyeloplasty in orthotopic kidneys $(18,19)$, the MIS approach offers the same advantages for both anatomical variants: an equivalent success rate to the open approach but with shorter convalescence. In orthotopic kidneys, MIS pyeloplasty has emerged as the 'gold standard' treatment for UPJ obstruction, leading to the evolution of robotic and LESS applications over the past decade $(2,3,20)$. These approaches will likely become more utilized for horseshoe UPJO into the future.

The primary technical challenges of pyeloplasty in this population relate to aberrant lower pole vessels, unfamiliar caudal position of the kidney, and the renal isthmus (21). Despite these anatomical challenges we believe that proficiency obtained during MIS repair in orthotopic kidneys reasonably translates into competency in horseshoe MIS pyeloplasty. To optimize success, anatomic complexities can be anticipated with appropriate preoperative imaging. A CT angiogram can accurately delineate the vasculature and collecting system (21). Magnetic resonance urography (MRU) can also be utilized for simultaneous evaluation of renal function and anatomy (22). One post-mortem study identified 
Table 4 - Comparison to other case series.

\begin{tabular}{lcccc}
\hline & Bove et al. (7) & Chammas et al. (17) & Lallas et al. (1) & Current Study \\
\hline Technique & $\begin{array}{c}\text { Conventional } \\
\text { Laparoscopic }\end{array}$ & Robotic & $\begin{array}{c}2 \text { Laparoscopic } \\
1 \text { Robotic }\end{array}$ & $\begin{array}{c}4 \text { Laparoscopic } \\
4 \text { Robotic } \\
1 \text { LESS }\end{array}$ \\
N & 5 & & 3 & 9 \\
OR time, min & 195 (mean) & 148.3 (mean) & 330 (mean) & $136[109,230]$ \\
Blood loss, mL & 122 (mean) & $<100$ (mean) & $<25$ (mean) & $12.5[5,50]$ \\
Length of Stay, days & 3.2 (mean) & 7.6 (mean) & 12.33 (mean) & $1.5[1,4]$ \\
Follow-up Duration, months & 4,13 (range) & 21 (mean) & 21.2 (mean) & $11[3,45]$ \\
Clinical success & $100 \%$ & $100 \%$ & $66.6 \%$ & $100 \%$ \\
Radiographic success & $100 \%$ & $100 \%$ & $66.6 \%$ & $78 \%$ \\
\hline
\end{tabular}

three groups of vessels in a horseshoe kidney that should be kept in mind; the main renal vessels, aberrant vessels to the isthmus, and accessory vessels to the poles (23). For standard cases, we prefer to obtain a CT scan with contrast and a baseline renogram to assess the pertinent anatomy and baseline function and drainage.

Laparoscopic pyeloplasty has been performed at our institution since 2000, while our first LESS pyeloplasty was performed in 2008. Robotic pyeloplasty in children was instituted within the past 2 years. This exemplifies the strong influence of the era of surgery as well as surgeon preference in choice of surgical approach. Perioperative outcomes mirrored those for laparoscopic, robotic and LESS pyeloplasty in orthotopic kidney $(1,17,24)$. As expected, the LESS approach required the most time while laparoscopy took slightly longer than robotics. A recent systematic review in orthotopic kidneys similarly suggested a 10 minutes operative time reduction for the robotic approach compared to laparoscopy, although this was not statistically significant (24). It is possible that the time saved from easier intracorporeal suturing with the ro- bot is lost by the longer time required for robot docking and setup.

The majority of our patients underwent a dismembered pyeloplasty while two pediatric patients successfully underwent a Hellstrom vascular hitch repair, as first described in 1949 (25). Horseshoe UPJ obstruction caused by an intrinsic stenosis, high ureteral insertion, or abnormal course of the ureter across the isthmus can be addressed by dismembered pyeloplasty (21). A crossing vessel causing obstruction in isolation can theoretically be treated with either a vascular hitch or dismembered pyeloplasty. Prior studies have suggested the best candidates for a Hellstrom repair are those with a crossing vessel and a normal caliber ureter with good peristalsis across the UPJ (8). In a series of 20 patients undergoing an MIS vascular hitch procedure, a success rate of 95\% was reported at a mean follow up of 22 months (8). While our experience and the experience of others $(26,27)$ suggests it is a reasonable approach in well selected patients of this unique population, its application remains controversial.

Robotic-LESS pyeloplasty may prove to be a valuable technique in the future. In a hor- 
seshoe kidney, the renal pelvis is located at the level of the umbilicus, directly below the single incision platform. This short working distance means very little lateral movement of instruments is required, making the procedure even more favorable than r-LESS in an orthotopic kidney. Furthermore, unlike c-LESS, an accessory lateral port is never required for suturing thanks to the robotic articulation that allows suturing through the single incision with relative ease.

This case series is limited by its small number, even smaller when divided by surgical approach, making impossible a meaningful statistical comparison to pyeloplasty in orthotopic kidneys. Due to the rarity of horseshoe kidney, large case series will take time to occur, which limits our ability to interpret the outcomes and/ or advantages of various techniques.

\section{CONCLUSIONS}

Success rates of MIS pyeloplasty in horseshoe kidneys may be inferior to those in heterotopic kidneys, although larger studies are required to allow for more accurate comparison. The choice of MIS approach may be influenced by surgeon experience, patient expectations, BMI and resource allocation, but each approach appears to be safe and technically feasible.

\section{CONFLICT OF INTEREST}

None declared.

\section{REFERENCES}

1. Lallas CD, Pak RW, Pagnani C, Hubosky SG, Yanke BV, Keeley FX, et al.: The minimally invasive management of ureteropelvic junction obstruction in horseshoe kidneys. World J Urol. 2011; 29: 91-5.

2. Schuessler WW, Grune MT, Tecuanhuey LV, Preminger GM: Laparoscopic dismembered pyeloplasty. J Urol. 1993; 150: 1795-9.

3. Erdeljan P, Caumartin Y, Warren J, Nguan C, Nott L, Luke PP, et al.: Robot-assisted pyeloplasty: follow-up of first Canadian experience with comparison of outcomes between experienced and trainee surgeons. J Endourol. 2010; 24: 1447-50.

4. El-Shazly MA, Moon DA, Eden CG: Laparoscopic pyeloplasty: status and review of literature. J Endourol. 2007; 21: 673-8.
5. Winfield HN: Management of adult ureteropelvic junction obstruction--is it time for a new gold standard? J Urol. 2006; 176: 866-7.

6. Janetschek G, Peschel R, Altarac S, Bartsch G: Laparoscopic and retroperitoneoscopic repair of ureteropelvic junction obstruction. Urology. 1996; 47: 311-6.

7. Bove P, Ong AM, Rha KH, Pinto P, Jarrett TW, Kavoussi LR: Laparoscopic management of ureteropelvic junction obstruction in patients with upper urinary tract anomalies. J Urol. 2004; 171: 77-9.

8. Gundeti MS, Reynolds WS, Duffy PG, Mushtaq I: Further experience with the vascular hitch (laparoscopic transposition of lower pole crossing vessels): an alternate treatment for pediatric ureterovascular ureteropelvic junction obstruction. J Urol. 2008; 180: 1832-6; discussion 1836.

9. Pitts WR Jr, Muecke EC: Horseshoe kidneys: a 40-year experience. J Urol. 1975; 113: 743-6.

10. Das S, Amar AD: Ureteropelvic junction obstruction with associated renal anomalies. J Urol. 1984; 131: 872-4.

11. Nguyen DH, Aliabadi H, Ercole CJ, Gonzalez R: Nonintubated Anderson-Hynes repair of ureteropelvic junction obstruction in 60 patients. J Urol. 1989; 142: 704-6.

12. Persky L, Krause JR, Boltuch RL: Initial complications and late results in dismembered pyeloplasty. J Urol. 1977; 118: 162-5.

13. Jabbour ME, Goldfischer ER, Stravodimos KG, Klima WJ, Smith AD: Endopyelotomy for horseshoe and ectopic kidneys. J Urol. 1998; 160: 694-7.

14. Nakamura K, Baba S, Tazaki H: Endopyelotomy in horseshoe kidneys. J Endourol. 1994; 8: 203-6.

15. Preminger GM, Clayman RV, Nakada SY, Babayan RK, Albala DM, Fuchs GJ, et al.: A multicenter clinical trial investigating the use of a fluoroscopically controlled cutting balloon catheter for the management of ureteral and ureteropelvic junction obstruction. J Urol. 1997; 157: 1625-9.

16. Shalhav AL, Giusti G, Elbahnasy AM, Hoenig DM, McDougall EM, Smith DS, et al.: Adult endopyelotomy: impact of etiology and antegrade versus retrograde approach on outcome. J Urol. 1998; 160: 685-9.

17. Chammas M Jr, Feuillu B, Coissard A, Hubert J: Laparoscopic robotic-assisted management of pelvi-ureteric junction obstruction in patients with horseshoe kidneys: technique and 1-year follow-up. BJU Int. 2006; 97: 579-83.

18. Janetschek G, Peschel R, Bartsch G: Laparoscopic Fenger plasty. J Endourol. 2000; 14: 889-93.

19. Siqueira TM Jr, Nadu A, Kuo RL, Paterson RF, Lingeman JE, Shalhav AL: Laparoscopic treatment for ureteropelvic junction obstruction. Urology. 2002; 60: 973-8.

20. Peters CA: Robotic pyeloplasty--the new standard of care? J Urol. 2008; 180: 1223-4.

21. Yohannes $P$, Smith $A D$ : The endourological management of complications associated with horseshoe kidney. J Urol. 2002; 168: 5-8. 
22. Mostafavi MR, Prasad PV, Saltzman B: Magnetic resonance urography and angiography in the evaluation of a horseshoe kidney with ureteropelvic junction obstruction. Urology. 1998; 51: 484-6.

23. Janetschek G, Kunzel KH: Percutaneous nephrolithotomy in horseshoe kidneys. Applied anatomy and clinical experience. Br J Urol. 1988; 62: 117-22.

24. Braga LH, Pace K, DeMaria J, Lorenzo AJ: Systematic review and meta-analysis of robotic-assisted versus conventional laparoscopic pyeloplasty for patients with ureteropelvic junction obstruction: effect on operative time, length of hospital stay, postoperative complications, and success rate. Eur Urol. 2009; 56: 848-57.

25. Hellstrom J, Giertz G, Lindblom K: Pathogenesis and treatment of hydronephrosis. J Belge Urol. 1951; 20: 1-6.

26. Meng MV, Stoller ML: Hellström technique revisited: laparoscopic management of ureteropelvic junction obstruction. Urology. 2003; 62: 404-8; discussion 408-9.
27. Simforoosh N, Javaherforooshzadeh A, Aminsharifi A, Soltani MH, Radfar MH, Kilani H: Laparoscopic management of ureteropelvic junction obstruction in pediatric patients: a new approach to crossing vessels, crossing vein division, and upward transposition of the crossing artery. J Pediatr Urol. 2010; 6: 161-5.

Correspondence address: Dr. Jeffrey A. Cadeddu Professor of Urology and Radiology Department of Urology University of Texas Southwestern Medical Center 5323 Harry Hines Blvd., J8.106, Dallas, TX 75390, USA

Fax: + 1214 648-8786

E-mail: jeffrey.cadeddu@utsouthwestern.edu 